\title{
The Impact of US Stock Market on the Co-Movements of BRIC Stock Markets Evidence from Linear Conditional Granger Causality
}

\author{
Lu Wang1, Yang Yang ${ }^{2 *}$, Yuanhui Ma1 \\ ${ }^{1}$ School of Mathematics, Southwest Jiaotong University, Chengdu, China \\ ${ }^{2}$ School of Economics and Management, Southwest Jiaotong University, Chengdu, China \\ Email: *1714810707@qq.com
}

How to cite this paper: Wang, L., Yang, Y. and Ma, Y.H. (2017) The Impact of US Stock Market on the Co-Movements of BRIC Stock Markets-Evidence from Linear Conditional Granger Causality. Open Journal of Statistics, 7, 849-858. https://doi.org/10.4236/ojs.2017.75060

Received: October 2, 2017

Accepted: October 24, 2017

Published: October 27, 2017

Copyright (๑) 2017 by authors and Scientific Research Publishing Inc. This work is licensed under the Creative Commons Attribution International License (CC BY 4.0).

http://creativecommons.org/licenses/by/4.0/

\begin{abstract}
This paper investigates the impact of the US stock market on the co-movements among the BRIC stock markets using conditional Granger causality which allows a comprehensive exploration on direct and indirect causality. The results from linear conditional causality test show a strong influence of the US stock market on the co-movements of BRIC. Our findings identify the US stock market which is the main inner factor making major contributions to the co-movements among the BRIC stock markets. Further, this study provides robust evidence that the co-movements cannot be significantly influenced by the common information factor. These findings show a more complete picture of the relationships between the US and the BRIC stock markets, offering important implications for policymakers and investors.
\end{abstract}

\section{Keywords}

Stock Market, BRIC, Co-Movement, Conditional Granger Causality

\section{Introduction}

The aim of this paper is to explore how the US stock market affects the co-movements of the BRIC stock markets. Lehkonen and Heimonen [1], Mensi et al. [2] and Xu and Hamori [3] have confirmed that the US stock market can have a profound impact on each of the BRIC markets. However, limited studies investigate the influence of the US market on the dependencies among the BRIC stock markets. The motivation of the study has crucial implications from various 
viewpoints. First, understanding the impact of the US stock market on the co-movements of BRIC stock markets allows investors to assess how it affects domestic and international portfolio diversification exposed to risks of stock price volatility. In this case, investors can adjust their asset allocation decisions according to the dynamic interactions between stock markets. Second, the interdependence of stock markets may be also relevant for portfolio managers and financial policymakers, because it implies that stock prices are influenced by common global factors, such as the US stock market, which can not be controlled only by local financial factors. Policymakers can formulate and implement appropriate management regulations to effectively cushion the impact of sharp fluctuations in the US stock market on the BRIC countries.

BRIC is an acronym for the combined countries of Brazil, Russia, India and China. Proposed originally by Jim O'Neill of Goldman Sachs in 2001, it is considered as the fastest growing market economies. Before being grouped as the BRIC countries, these countries were for a long time on the periphery of the global economy. Following Bekiros [4], they are now almost looked as a unit in the international financial markets. Cheng et al. [5] and Syriopoulos et al. [6] demonstrate that the BRIC stock markets have grown stupendously in terms of increase in size and volume of investment by both domestic and international investors over the past 10 years.

In contrast to these previous studies, in this paper we first investigate whether the price of US stock market can affect the linkages among the BRIC stock markets. The prime motivation for choosing the US stock market comes from the fact that it plays a critical role in the global economy as a representative leading mature market [7] and therefore our motivation appears meaningful. Regarded the US stock market as a transmission channel, the fluctuations in the world macroeconomic environment, such as financial liberalization, could be passed to the BRIC countries and affect the co-movements of the stock markets.

Granger causality now provides a flexible, efficient and powerful method for exploring the co-movements of stock markets [8] [9] [10]. However, the Granger causality is applicable only to bivariate stock market returns. In multivariable situations, one stock market can be influenced by another market in a direct or an indirect manner. For instance, one market may falsely appear to cause another if they are both impacted by a third stock market. To address this issue, Geweke [11] [12] introduce conditional Granger causality which can detect the conditional causal relationship between multivariable time series. Therefore, the conditional relationship should be also taken into account when we investigate the conditional causality between the stock markets. Accordingly, this paper examines the Granger causality among the BRIC stock markets after proper subtraction of the impact of the US stock market on the BRIC countries.

As compared with previous studies, the main contribution in this paper is following: we apply unconditional and conditional Granger causality approach to explore the linkages among the BRIC countries. Comparing the differences between the results of unconditional and conditional methods, we address the fol- 
lowing questions: whether the price of the US stock market has a significant influence on the co-movements of BRIC countries? How the US stock market impact the co-movements of the BRIC stock markets? To the best of our knowledge, there are no papers answering the two questions above.

The remaining part of this paper is organized as follows. Section 2 introduces the methodology applied in the paper. Section 3 shortly describes the data used. Section 4 provides and discusses the empirical results. Finally, Section 6 offers conclusions.

\section{Methodology}

Granger causality analysis was proposed by Granger [13] and Sims [14] and is now widely applied to examine the causal relationship between two random variables. The Granger causality test investigates whether the historical information of one variable could help improve the ability to predict the present and future estimation for another variable. Consider that $\left\{X_{t}, Y_{t} ; t \geq 1\right\}$ are two stationary and ergodic time series processes, $F_{X, t}$ and $F_{Y, t}$ denote the information sets including the past values of $X_{t}$ and $Y_{t}$ before time $t+1$. Then $\left\{X_{t}\right\}$ is said to Granger cause $\left\{Y_{t}\right\}$ if, for $k \geq 1$ :

$$
\left(Y_{t+1}, \cdots, Y_{t+k}\right)\left|\left(F_{X, t}, F_{Y, t}\right) \sim\left(Y_{t+1}, \cdots, Y_{t+k}\right)\right| F_{X, t}
$$

where " " is equivalence in distribution.

The unconditional Granger causality testing introduced above can show spurious causality between $X$ and $Y$ if there is an apparent impact of a third variable, $Z$ say, on $X$ and $Y$. For instance, if there is no direct causal relationship from $X$ to $Y$ but there are strong dependencies of $X$ and $Y$ on $Z$, then a spurious causality from $X$ to $Y$ may be reported under the influence of $Z$. The spurious causality from $X$ to $Y$ may be eliminated by the dependencies between $X$ and $Z$ and between $Y$ and $Z$ subtracted. To deal properly with the general spurious case, the conditional Granger causality was introduced by Geweke [12].

To explain the conditional case, $\left\{X_{t}, Y_{t}, Z_{t} ; t \geq 1\right\}$ denote three stationary and ergodic time series processes, and we wish to eliminate any joint impact of $Z$ on the inference of the Granger causality from $Y$ to $X$. Next we can consider the full and reduced regressions as follows with the conditioning variables $Z_{t}$ included in both regressions

$$
\begin{gathered}
X_{t}=\sum_{k=1}^{p} A_{x x, k} \cdot X_{t-k}+\sum_{k=1}^{p} A_{x y, k} \cdot Y_{t-k}+\sum_{k=1}^{p} A_{x z, k} \cdot Z_{t-k}+\varepsilon_{x, t} \\
X_{t}=\sum_{k=1}^{p} A_{x x, k}^{\prime} \cdot X_{t-k}+\sum_{k=1}^{p} A_{x z, k}^{\prime} \cdot Z_{t-k}+\varepsilon_{x, t}^{\prime}
\end{gathered}
$$

where matrices $A_{.,{ }_{k}}$ are the regression coefficients, and the stochastic process $\varepsilon_{.,,_{t}}$ are the residuals. Technically, the null hypothesis of zero causality is as follows:

$$
H_{0}: A_{x y, 1}=A_{x y, 2}=\cdots=A_{x y, p}=0
$$

Similarly to the definition of the unconditional Granger causality statistic as the appropriate log-likelihood ratio [15] [16], the causality from $Y_{t}$ to $X_{t}$ condi- 
tioned on $Z_{t}$ is defined as following:

$$
F_{Y \rightarrow X \mid Z} \equiv \ln \frac{\left|\Sigma_{X X}^{\prime}\right|}{\left|\Sigma_{X X}\right|}
$$

where $\Sigma_{x x}=\operatorname{cov}\left(\varepsilon_{X, t}\right)$ and $\Sigma_{x x}^{\prime}=\operatorname{cov}\left(\varepsilon_{X, t}^{\prime}\right)$ are the residuals covariance matrices of the regression models Equations ((2) and (3)), respectively. $F_{Y \rightarrow X \mid Z}$ in Equation (5) is considered as a log likelihood ratio test, comparing models with and without the directed causal relation from $Y$ to $X$.

If the causal effect from $Y$ to $X$ is entirely subtracted by the third time series $Z$, the test $F_{Y \rightarrow X \mid Z}=0$, which means that no more improvement in the predication of $X$ can be expected by including the past of $Y$ conditioned on $Z$. On the contrary, the test $F_{Y \rightarrow X \mid Z}>0$ if the direct causal effect from $Y$ to $X$ exists, which indicates that the past of $Y$ conditioned on $Z$ can help to improve the predication of $X$.

The standard large-sample theory [17] can be applied to the conditional Granger causality as a likelihood ratio test. Assume $\operatorname{dim}(X)=n_{x}, \operatorname{dim}(Y)=n_{y}$ and $\operatorname{dim}(Z)=n_{z}$ (with $n_{x}+n_{y}+n_{z}=n$ ), the difference in the number of parameters between the full model (2) and the nested reduced model (3) is just $d \equiv p n_{x} n_{y}$. Thus under the null hypothesis (4) of zero causal effect, $(m-p) F_{Y \rightarrow X \mid Z}$, the test statistic for conditional Granger causality scaled by sample size has an asymptotic $\chi^{2}(d)$ distribution.

\section{Data and Preliminary Analysis}

The data in this study consist of five time series of daily stock price indices denoted relative to United States (US), Brazil (BR), Russia (RS), India (IN) and China $(\mathrm{CH})$, respectively. The sample covers the period from September 18, 2007 to September 30, 2015, with 1696 observations for each stock market. All indices were all taken from the Yahoo! website (http://finance.yahoo.com), and the stock returns are expressed as $r_{t}=\ln P_{t}-\ln P_{t-1}$, where $P_{t}$ is the stock price index at time $t$. In order to compensate for missing values in the returns for each of the countries, we exclude the corresponding observations in all of the returns.

Table 1 summarizes the descriptive statistics for daily returns of the US and BRIC stock markets. The average stock returns are negative for the BRIC markets, except for India which has a positive average return. On the other hand, the

Table 1. Descriptive statistics for the US and the BRIC stock markets return.

\begin{tabular}{cccccccccc}
\hline & Mean & Maximum & Minimum & S.D & Skewness & Kurtosis & J-B & ADF & PP \\
\hline US & 0.00015 & 0.0913 & -0.0947 & 0.0144 & -0.5234 & 9.576 & $3131.8^{* * *}$ & $-26.7222^{* * *}$ & $-46.2120^{* * *}$ \\
BR & -0.00011 & 0.1687 & -0.1209 & 0.0195 & 0.1565 & 10.732 & $4229.2^{* * *}$ & $-26.1905^{* * *}$ & $-41.8285^{* * *}$ \\
RS & -0.00052 & 0.2020 & -0.2119 & 0.0265 & -0.3815 & 13.140 & $7302.9^{* * *}$ & $-23.4252^{* * *}$ & $-37.1160^{* * *}$ \\
IN & 0.00033 & 0.1503 & -0.1752 & 0.0167 & -0.7276 & 17.027 & $14046.0^{* * *}$ & $-23.7181^{* * *}$ & $-39.8264^{* * *}$ \\
CH & -0.00034 & 0.0925 & -0.1918 & 0.0193 & -1.0823 & 13.785 & $8545.8^{* * *}$ & $-22.2638^{* * *}$ & $-41.4320^{* * *}$ \\
\hline
\end{tabular}

Notes: J-B is the empirical statistic of the Jarque-Bera test for normality.ADF and PP are the empirical statistics of the Augmented Dickey-Fuller unit root test and the Phillips and Perron unit root test, respectively. 
standard deviations of all returns range from 0.0167 to 0.0265 . Russia exhibits comparatively higher risk. On the contrary, the US stock market displays the lowest volatility level among the selected stock markets. The stock market of Russia shows the maximum and the minimum returns among the BRIC markets, which implies a strenuous fluctuation. Negative skewness are observed for all BRIC countries with the exception of Brazil which has a positive skewness. All return series exhibit excess kurtosis. Furthermore, the J-B test shows that the null of normality is strongly rejected for all returns. Finally, the results of time series stationarity test, by applying the ADF and PP statistics, identify all of time series are stationary.

To examine the co-movements among the stock returns, we employ the Pearson correlation coefficient to calculate correlations between the BRIC stock markets, which can be expressed as:

$$
\rho(i, j)=\frac{\left\langle r_{i}-\mu_{i}\right\rangle\left\langle r_{j}-\mu_{j}\right\rangle}{\sigma_{i} \sigma_{j}}
$$

where $r_{i}$ and $r_{j}$ are the returns for stock $i$ and $j, \mu_{i}$ and $\mu_{j}$ are the means, $\sigma_{i}$ and $\sigma_{j}$ are the standard deviations, and \langle\rangle is defined to be the average over time.

Table 2 reports the Pearson correlations for all BRIC return series. As shown, all correlations are positive and highly statistically significant which is significant at $1 \%$ level. This implies the stock markets of BRIC do exhibit a significant degree of integration with each other in accordance with Bhar and Nikolova [18]. The increased international capital flows and the growing migration of stock market activities to international stock markets have increased the degree of integration among the BRIC stock markets.

\section{Empirical Results}

Since all of the returns are stationary, the VAR model is first applied to model the bivariate data of the BRIC stock returns. The lags are determined by minimizing AIC for the VAR model. Table 3 presents the empirical results of the

Table 2. Unconditional and conditional correlations of the BRIC stock markets.

\begin{tabular}{|c|c|c|c|}
\hline & $\mathrm{BR}$ & RS & IN \\
\hline \multicolumn{4}{|c|}{ Panel A:unconditional } \\
\hline RS & $0.499^{* * *}$ & & \\
\hline IN & $0.330^{* * *}$ & $0.432^{* * *}$ & \\
\hline $\mathrm{CH}$ & $0.196^{\star * *}$ & $0.227^{\star * *}$ & $0.273^{* * *}$ \\
\hline \multicolumn{4}{|c|}{ Panel B:conditional } \\
\hline RS & $0.288^{* * *}$ & & \\
\hline IN & $0.184^{* * *}$ & $0.353^{\star * *}$ & \\
\hline $\mathrm{CH}$ & $0.184^{\star * *}$ & $0.207^{* * *}$ & $0.258^{\star * *}$ \\
\hline
\end{tabular}

Notes: ${ }^{* *}$ indicates statistical significance at $1 \%$ level. 
Table 3. The optimal lag orders of fitted VAR models.

\begin{tabular}{ccccc}
\hline & BR & RS & IN & CH \\
\hline BR & c & & & \\
RS & 1 & - & 2 & 5 \\
IN & 1 & 1 & - & 9 \\
$\mathrm{CH}$ & 1 & 1 & 1 & - \\
\hline
\end{tabular}

Notes: Unconditional linear Granger causality (above diagonal) and conditional linear Granger causality (below diagonal).

unconditional Granger causality(UGC) and conditional Granger causality(CGC) among the BRIC stock markets, where the F-statistics are provided. The results from the unconditional Granger causality show that the significant causality is found between the BRIC. The significant bidirectional causality is only observed in the case of Brazil and Russia, Brazil and India, China and India, and China and Russia. At 1\% level of significance, results indicate the causality from Brazil to China and from Russia to India, respectively.

Moreover, we find a remarkable difference between the results of the unconditional and conditional Granger causality. Comparing the results from the unconditional Granger causality, the following significant unidirectional linear causal relationships do not exist in the results of the conditional Granger causality: from Brazil to China, from Russia to India, and from China to Russia. For instance, the Brazilian stock market exhibits a strong unconditional linear effect on the Chinese stock market. However, this causal relationship does not exist when the effect of the US stock market subtracted, which implies the causality can change from direct to indirect. The results show that when we examine the co-movements, we cannot ignore the effect of the US market, which definitely have a great influence on the linkage among the BRIC stock markets. This finding reflects the leading role of the US stock market in the international financial market, since it is considered as a "global factor" influencing all countries [19]. For instance, Kotkatvuori-Ornberg et al. [20] confirm empirical findings that the financial crisis originated from the US in 2008 has a significant influence on a total of 50 international stock markets in different regions of the world. This implies that as the world's largest stock market, the US can drive strong movements on emerging and frontier markets all over the world, including the stock markets of BRIC.

As shown in Table 4, some of the results of both unconditonal and conditional linear Granger causality tests support the same conclusion, for instance, the causality between Brazil and Russia and between China and India. The same results indicate, whether considering the influence of the US stock market, the causal relationships between some countries of BRIC can maintain unchanged. This suggests that the existence of strong economic relationships among the BRIC countries under the trend of financial globalization [21]. Therefore, the fluctuation of the US stock market is merely one of the important factors to af- 
Table 4. Unconditional and conditional linear causality between the stock markets of BRIC.

\begin{tabular}{cccccccccc}
\hline & \multicolumn{3}{c}{ BR } & \multicolumn{2}{c}{ RS } & & IN & CH & \\
\cline { 2 - 9 } & UGC & CGC & UGC & CGC & UGC & CGC & UGC & CGC \\
\hline BR & & & $23.2826^{* * *}$ & $0.0044^{* * *}$ & $16.7573^{* *}$ & $2.4500 \times 10^{-4}$ & 8.6479 & $7.5808 \times 10^{-7}$ \\
RS & $92.4775^{* * *}$ & $0.0144^{* * *}$ & & & & 1.06576 & $6.9221 \times 10^{-5}$ & $12.0172^{* *}$ & $4.8059 \times 10^{-4}$ \\
IN & $81.0052^{* * *}$ & $0.0029^{* * *}$ & $17.8488^{* * *}$ & $4.6742 \times 10^{-5}$ & & & & $22.9761^{* * *}$ & $0.0025^{* * *}$ \\
CH & $76.7734^{* * *}$ & $3.7667 \times 10^{-4}$ & $31.1568^{* * *}$ & $0.0055^{* * *}$ & $35.7090^{* * *}$ & $0.0059^{* * *}$ & & \\
\hline
\end{tabular}

Notes: Significant $\left({ }^{* *},{ }^{* *}\right.$ or $\left.{ }^{\star}\right)$ entries indicate that stock market $\mathrm{X}$ (top row) has a causal linear relationship with stock market $\mathrm{Y}$ (left column), i.e. $\mathrm{X} \rightarrow \mathrm{Y} .{ }^{*}$, ${ }^{* *}$ and ${ }^{* * *}$ indicate statistical significance at $10 \%, 5 \%$ and $1 \%$ levels, respectively.

fect the relationships across the BRIC stock market. The results are similar to Mensi et al. [2]. They find the BRIC countries show a strong linkage not only with the world stock markets, but also with the global commodity markets(oil and gold).

\section{Robustness Tests}

According to Asimakopoulos et al. [22], the causal relationships can be driven by a common informational factor which is assumed to be the persistence in variance. To make sure our results more robust, we implement a GARCH $(1,1)$ model filtering on the return to capture the common factor, and the corresponding residuals are explored pairwise by the unconditional and conditional Granger causality.

We detect the nonlinear causal relationships among the BRIC stock market in the GARCH $(1,1)$ filtered residual series by using BDS test. The BDS test can help to explore the nonlinear serial dependence in time series. The results of BDS test in Table 5 indicate that even the $\operatorname{GARCH}(1,1)$ filtered series still have nonlinear dependencies. Table 6 presents the results of the unconditional and conditional Granger causality test under the linear condition. We find the results of the causality from GARCH $(1,1)$ model in Table 6 are consistent with the results in Table 4. Moreover, the most same results of causality before and after GARCH $(1,1)$ filtering indicate the co-movements among the BRIC stock markets can not be significantly influenced by the common factor, which further tests the robustness of the results in this paper.

\section{Conclusions}

This paper provides fresh new insights into the co-movements among the BRIC stock markets from 2007 to 2015, applying the novel conditional Granger causality analysis. The existing literature concentrates on the relationships among the BRIC markets but, in reality, the co-movements may be affected by the US stock market. Using conditional linear Granger causality test, we examine how the US stock market impacts the co-movements among the BRIC stock markets, which allows a comprehensive exploration on direct and indirect causality. We provide evidence that there is conditional causality among the BRIC markets, 
Table 5. BDS test from the GARCH $(1,1)$ filtered series of the US and BRIC stock markets.

\begin{tabular}{cccccc}
\hline \multirow{2}{*}{$\begin{array}{c}\text { Embedding } \\
\text { dimension }(\mathrm{m})\end{array}$} & \multicolumn{3}{c}{ BDS statistics for the US and BRIC } \\
\cline { 2 - 5 } & $\mathrm{BR}$ & $\mathrm{RS}$ & $\mathrm{IN}$ & $\mathrm{CH}$ & US \\
\hline 2 & $0.0137^{* * *}$ & $0.0265^{* * *}$ & $0.0215^{* * *}$ & $0.0138^{* * *}$ & $0.0226^{* * *}$ \\
3 & $0.0302^{* * *}$ & $0.0509^{* * *}$ & $0.0419^{* * *}$ & $0.0314^{* * *}$ & $0.0505^{* * *}$ \\
4 & $0.0402^{* * *}$ & $0.0703^{* * *}$ & $0.0580^{* * *}$ & $0.0483^{* * *}$ & $0.0726^{* * *}$ \\
5 & $0.0468^{* * *}$ & $0.0828^{* * *}$ & $0.0689^{* * *}$ & $0.0581^{* * *}$ & $0.0874^{* * *}$ \\
6 & $0.0509^{* * *}$ & $0.0892^{* * *}$ & $0.0737^{* * *}$ & $0.0628^{* * *}$ & $0.0952^{* * *}$ \\
\hline
\end{tabular}

Notes: ${ }^{* * *}$ Represents significant nonlinear dependencies at $1 \%$ level of significance.

Table 6. Unconditional and conditional linear causality between BRIC stock markets from GARCH $(1,1)$ model.

\begin{tabular}{|c|c|c|c|c|c|c|c|c|}
\hline & \multicolumn{2}{|c|}{$\mathrm{BR}$} & \multicolumn{2}{|c|}{ RS } & \multicolumn{2}{|c|}{ IN } & \multicolumn{2}{|c|}{$\mathrm{CH}$} \\
\hline & UGC & CGC & UGC & CGC & UGC & CGC & UGC & CGC \\
\hline $\mathrm{BR}$ & & & $16.1253^{* * *}$ & $0.0146^{* * *}$ & $15.9924^{*}$ & $5.4387 \times 10^{-4}$ & 7.3876 & $1.2869 \times 10^{-7}$ \\
\hline RS & $90.4195^{\star * *}$ & $8.1959 \times 10^{-4 \star *}$ & & & 0.5711 & $6.4264 \times 10^{-5}$ & $10.0208^{\star *}$ & $7.4022 \times 10^{-6}$ \\
\hline IN & $71.2210^{* * *}$ & $0.0012^{* *}$ & $16.0341^{* * *}$ & $4.4591 \times 10^{-5}$ & & & $15.4877^{\star \star}$ & $0.0021^{\star * *}$ \\
\hline $\mathrm{CH}$ & $72.5070^{* * *}$ & $4.6307 \times 10^{-4}$ & $21.6095^{* * *}$ & $0.0041^{* * *}$ & $33.4177^{* * *}$ & $0.0028^{* * *}$ & & \\
\hline
\end{tabular}

Notes: Significant $\left({ }^{* *},{ }^{* *}\right.$ or $\left.^{\star}\right)$ entries indicate that stock market $\mathrm{X}$ (top row) has a causal linear relationship with stock market $\mathrm{Y}$ (left column), i.e. $\mathrm{X} \rightarrow \mathrm{Y}$.

which reveals more complex interaction relations on a deeper level.

Our results show a strong influence of the US stock market on the co-movements of BRIC. We also uncover evidence of wide variation in causal relations across the BRIC stock markets without taking into account the influence of the US. This identifies the US stock market is the main inner factor making major contributions to the linkage mechanism among the BRIC countries. The global dominance of the US stock market may have significantly affected the co-movements among emerging markets. In particular, we find that some of the causal relationships still remain unchanged regardless of the impact of the US stock market. A possible explanation is that there exists a limited effect of the US stock market on the co-movements, since there exist other major global economic and financial factors that can affect the relationships among the BRIC markets, e.g., the oil prices, the gold prices and VIX. Further research is needed to examine what impact the co-movements of the BRIC stock markets.

Overall, our findings in the paper have two key implications for international investors and portfolio managers. First, the asset alocation decisions should not ignore the influence of the US stock market on the co-movements among the BRIC countries, which can remind the investors to be more cautious when they plan to invest in simultaneous financial markets that exhibit pure contagion. Second, awareness of the impact of the US stock market is important for policymakers to pay more attention to the directions and degrees of the co-movements in order to better manage and control market risks to prevent future financial crises. 


\section{Acknowledgements}

This research was supported by the MOE Project of Humanities and Social Sciences (17XJCZH002) and Student Research Training Program in Southwest Jiaotong University (201710613075).

\section{References}

[1] Lehkonen, H. and Heimonen, K. (2014) Timescale-Dependent STOCK Market Comovement: BRICs vs. Developed Markets. Journal of Empirical Finance, 28, 90-103. https://doi.org/10.1016/j.jempfin.2014.06.002

[2] Mensi, W., Hammoudeh, S., Reboredo, J.C. and Nguyen, D.K. (2014) Do Global Factors Impact BRICS Stock Markets? A Quantile Regression Approach. Emerging Markets Review, 19, 1-17. https://doi.org/10.1016/j.ememar.2014.04.002

[3] Xu, H. and Hamori, S. (2012) Dynamic Linkages of Stock Prices between the BRICs and the United States: Effects of the 2008-09 Financial Crisis. Journal of Asian Economics, 23, 344-352. https://doi.org/10.1016/j.asieco.2012.04.002

[4] Bekiros, S.D. (2014) Contagion, Decoupling and the Spillover Effects of the US Financial Crisis: Evidence from the BRIC Markets. International Review of Financial Analysis, 33, 58-69. https://doi.org/10.1016/j.irfa.2013.07.007

[5] Cheng, H.F., Gutierrez, M., Mahajan, A., Shachmurove, Y. and Shahrokhi, M. (2007) A Future Global Economy to Be Built by BRICs. Global Finance Journal, 18, 143-156. https://doi.org/10.1016/j.gfj.2006.04.003

[6] Syriopoulos, T., Makram, B. and Boubaker, A. (2015) Stock Market Volatility Spillovers and Portfolio Hedging: BRICS and the Financial Crisis. International Review of Financial Analysis, 39, 7-18. https://doi.org/10.1016/j.irfa.2015.01.015

[7] Rapach, D.E., Strauss, J.K. and Zhou, G. (2013) International Stock Return Predictability: What Is the Role of the United States? The Journal of Finance, 68, 1633-1662. https://doi.org/10.1111/jofi.12041

[8] Choudhry, T., Hassan, S.S. and Shabi, S. (2015) Relationship between Gold and Stock Markets during the Global Financial Crisis: Evidence from Nonlinear Causality Tests. International Review of Financial Analysis, 41, 247-256. https://doi.org/10.1016/j.irfa.2015.03.011

[9] Huang, B.N., Yang, C.W. and Hu, J.W.S. (2000) Causality and Cointegration of Stock Markets among the United States, Japan and the South China Growth Triangle. International Review of Financial Analysis, 9, 281-297. https://doi.org/10.1016/S1057-5219(00)00031-4

[10] Granger, C.W., Huangb, B.N. and Yang, C.W. (2000) A Bivariate Causality between Stock Prices and Exchange Rates: Evidence from Recent Asianflu. The Quarterly Review of Economics and Finance, 40, 337-354. https://doi.org/10.1016/S1062-9769(00)00042-9

[11] Geweke, J. (1982) Measurement of Linear Dependence and Feedback between Multiple Time Series. Journal of the American Statistical Association, 77, 304-313. https://doi.org/10.1080/01621459.1982.10477803

[12] Geweke, J.F. (1984) Measures of Conditional Linear Dependence and Feedback between Time Series. Journal of the American Statistical Association, 79, 907-915. https://doi.org/10.1080/01621459.1984.10477110

[13] Granger, C.W. (1969) Investigating Causal Relations by Econometric Models and Cross-Spectral Methods. Econometrica: Journal of the Econometric Society, 37, 
424-438. https://doi.org/10.2307/1912791

[14] Sims, C.A. (1972) Money, Income, and Causality. The American Economic Review, $62,540-552$.

[15] Barrett, A.B., Barnett, L. and Seth, A.K. (2010) Multivariate Granger Causality and Generalized Variance. Physical Review E, 81, Article ID: 041907. https://doi.org/10.1103/PhysRevE.81.041907

[16] Barnett, L. and Seth, A.K. (2011) Behaviour of Granger Causality under Filtering: Theoretical Invariance and Practical Application. Journal of Neuroscience Methods, 201, 404-419. https://doi.org/10.1016/j.jneumeth.2011.08.010

[17] Wald, A. (1943) Tests of Statistical Hypotheses Concerning Several Parameters When the Number of Observations Is Large. Transactions of the American Mathematical Society, 54, 426-482. https://doi.org/10.1090/S0002-9947-1943-0012401-3

[18] Bhar, R. and Nikolova, B. (2009) Oil Prices and Equity Returns in the BRIC Countries. The World Economy, 32, 1036-1054. https://doi.org/10.1111/j.1467-9701.2009.01194.x

[19] Pevzner, M., Xie, F. and Xin, X. (2015). When Firms Talk, Do Investors Listen? The Role of Trust in Stock Market Reactions to Corporate Earnings Announcements. Journal of Financial Economics, 117, 190-223.

[20] Kotkatvuori-Örnberg, J., Nikkinen, J. and Äijö, J. (2013) Stock Market Correlations during the Financial Crisis of 2008-2009: Evidence from 50 Equity Markets. International Review of Financial Analysis, 28, 70-78.

https://doi.org/10.1016/j.irfa.2013.01.009

[21] Kunnanatt, J.T. (2013) Globalization and Developing Countries: A Global Participation Model. Economics, Management and Financial Markets, 8, 42.

[22] Asimakopoulos, I., Ayling, D. and Mahmood, W.M. (2000) Non-Linear Granger Causality in the Currency Futures Returns. Economics Letters, 68, 25-30.

https://doi.org/10.1016/S0165-1765(00)00219-6 